OPEN ACCESS

Edited by:

Jessica Blois,

University of California, Merced

United States

Reviewed by:

Thomas W. Swetnam,

University of Arizona, United States

Jess K. Zimmerman,

University of Puerto Rico, Puerto Rico

${ }^{*}$ Correspondence:

Erica A. Newman

newmane@email.arizona.edu

Specialty section:

This article was submitted to Biogeography and Macroecology,

a section of the journal

Frontiers in Ecology and Evolution

Received: 29 November 2018

Accepted: 15 April 2019

Published: 10 May 2019

Citation:

Newman EA (2019) Disturbance Ecology in the Anthropocene.

Front. Ecol. Evol. 7:147.

doi: 10.3389/fevo.2019.00147

\section{Disturbance Ecology in the Anthropocene}

\author{
Erica A. Newman * \\ Department of Ecology and Evolutionary Biology, University of Arizona, Tucson, AZ, United States
}

With the accumulating evidence of changing disturbance regimes becoming increasingly obvious, there is potential for disturbance ecology to become the most valuable lens through which climate-related disturbance events are interpreted. In this paper, I revisit some of the central themes of disturbance ecology and argue that the knowledge established in the field of disturbance ecology continues to be relevant to ecosystem management, even with rapid changes to disturbance regimes and changing disturbance types in local ecosystems. Disturbance ecology has been tremendously successful over the past several decades at elucidating the interactions between disturbances, biodiversity, and ecosystems, and this knowledge can be leveraged in different contexts. Primarily, management in changing and uncertain conditions should be focused primarily on the long-term persistence of that native biodiversity that has evolved within the local disturbance regime and is likely to go extinct with rapid changes to disturbance intensity, frequency, and type. Where possible, conserving aspects of natural disturbance regimes will be vital to preserving functioning ecosystems and to that native biodiversity that requires disturbance for its continued existence, though these situations may become more limited over time. Finally, scientists must actively propose management policies that incorporate knowledge of disturbance ecology. Successful policies regarding changing disturbance regimes for biodiversity will not merely be reactive, and will recognize that for natural ecosystems as for human society, not all desired outcomes are simultaneously possible.

\footnotetext{
Keywords: anthropogenic change, disturbance ecology, disturbance regimes, landscape ecology, natural disturbances, wildfire
}

\section{INTRODUCTION}

Monica Turner's article "Disturbance and Landscape Dynamics in a Changing World" (2010) summarized the importance of disturbance ecology and discussed how the field is poised to lead the way to new insights in ecology during the coming period of global change. Because disturbance ecology directly studies disturbance events, landscape dynamics, and processes that both influence and respond to environmental heterogeneity, it is ideally suited to say how these relationships and events might change with climate forcing and other aspects of environmental change. Looking toward this decidedly different future, Turner wrote that "disturbance regimes will likely move into uncharted territory" with unknown consequences and possible surprises, but points out that "[d]isturbances will continue to provide valuable opportunities for gaining insights about patternprocess interactions." We have arrived in that uncharted territory in under a decade since the writing of that article, and the framework, challenges, and research priorities that Turner laid out 
in 2010 are now even more relevant. The potential is high for disturbance ecology to become the most valuable lens through which climate-related disturbance events are seen and understood.

The accumulating evidence of changing disturbance regimes is becoming increasingly obvious, with large shifts in characteristics of individual disturbances and disturbance regimes (Webster et al., 2005; Johnstone et al., 2016; Sommerfeld et al., 2018), and more changes predicted for the future (Meehl and Tebaldi, 2004; Moritz et al., 2012; Allen et al., 2015). Hurricanes are not necessarily changing in number, but there has been an increase in the number of intense hurricanes in the past 40 years (based on wind speed and storm surges), and hurricanes produce more rainfall overall (Webster et al., 2005; IPCC, 2014; Emanuel, 2018). Wildfire has been changing and will continue to change in a variety of ways due to climate change and land-use practices, including increases in burned area and fire intensity in many regions (Flannigan et al., 2013), and increases in fire frequency (e.g., Pausas and Vallejo, 1999; Syphard et al., 2009) and locations of fires in other regions (Balch et al., 2017). Interactions between drought and fire may increase fire activity generally (Littell et al., 2009) but lead to decreases in fire frequency where terrestrial systems are becoming too arid to support vegetation (Moritz et al., 2012; McKenzie and Littell, 2017). Interactions between drought and high temperatures are leading to greatly increased tree mortality globally (Allen et al., 2015; Matusick et al., 2018). All these changes in disturbance regimes are occurring concurrently with anthropogenic alternations of the global ecosystem such as global rises in temperatures, increased mass pollution events, defaunation of ecosystems, increases in wildland conversion for human use, and intensification of use of converted lands. We expect some if not all of these trends to continue. It is also likely that new disturbance regimes will arise, including the possibility of new types of disturbances that involve plastics, toxins, and agricultural chemicals. Disturbance regimes will interact with one another in entirely new ways and in new places, including in oceans and other water bodies, where our understanding of disturbance regimes and anthropogenic impacts is poor (Bowler et al., 2018). As we continue to study and monitor disturbance regimes, we may also identify new interactions among them.

This Perspective is meant to revisit some of the central themes of disturbance ecology and discuss pressing challenges facing scientists, including their role in how disturbances are interpreted for policy and management. Specifically, I argue here that (a) pre- and post-disturbance management of ecosystems should be focused primarily on the long-term persistence of native biodiversity that has evolved within the local disturbance regime (hereafter "native biodiversity"); (b) where possible, conserving aspects of natural disturbance regimes is vital to preserving functioning ecosystems and native biodiversity; and (c) scientists not only will face the usual challenges of advocating science-based policy with government and civil society actors but also must actively propose management policies that incorporate knowledge of disturbance ecology.

\section{WHAT IS DISTURBANCE, AND WHAT ARE DISTURBANCE REGIMES?}

Disturbance is a useful term, and it is used both within and outside of ecology colloquially to mean an event that causes a departure from a normal or desired state, or an unwanted source of stochasticity in an otherwise controlled experiment or system. But within the field of disturbance ecology, the term disturbance refers to something more scientifically tractable and less normative. A useful and widely accepted definition of a disturbance (also used here) is "any event that is relatively discrete" in time and space "that disrupts the structure of an ecosystem, community, or population, and changes resource availability or the physical environment" (White and Pickett, 1985). Natural disturbances cause mortality of some of-but not all of - the biological organisms making up the communities in an ecosystem, or the larger metacommunity. Furthermore, the term natural disturbance is often used to mean something more specific than a disturbance event that is natural in origin (as the name would imply), and is instead used to refer to a disturbance event that is part of a historical disturbance regime. There are many aspects of disturbance regimes that allow them to be characterized and compared to one another, but those that are generally recognized as most important are their type, expected size, season, return interval, severity (or degree of mortality), and interactions with other disturbance regimes (White and Pickett, 1985; Turner and Dale, 1998; Turner, 2010). These characteristics encompass not only the average conditions for each of these measures but also their historical range of variability (HRV), or natural variability. Climate change may differentially affect the mean, range, and variability of disturbance conditions.

Given that the field of disturbance ecology was developed within the Anthropocene era (Waters et al., 2016) - an era that is itself demarcated from the previous era by rapid change of the environment and departure from the previous era of relative climate stability-it may seem surprising to talk about natural disturbances and disturbance regimes as somewhat fixed characteristics of ecosystems. But by using the above definitions of natural disturbances and disturbance regimes, we have been able to create benchmarks for comparing past, current, and future disturbance regimes to each other and to reference conditions defined as prior to the proposed beginning date of the Anthropocene (Landres et al., 1999). This gains us two elements of anchoring stability into the disturbance ecology framework. First, we are able to make use of the historical records available through more classic sources, including fire records, tree-ring data, and paleoecological evidence (including lake cores and pollen records), as well as indigenous knowledge of the natural history of species. This allows historical comparisons but also provides context for current and future management (Morgan et al., 1994; Keane et al., 2009). Second, this formulation of natural disturbances also allows the integration of one of the more underappreciated aspects of disturbance regimes, which is that they impose selective pressures of the organisms that live within them and therefore influence adaptation and evolutionary trajectories of taxa (see, for example, Schwilk and Ackerly, 
2001). Such information can be used for planning conservation of individual species and entire ecosystems (Attiwill, 1994; Hessburg et al., 2004; Mori, 2011) and can also be used in forecasting vegetation under future climate change scenarios. Third, with the idea that there is a useable reference period for the HRV of disturbance regimes, we can distinguish somewhat normal patterns from "large, infrequent disturbances" that fall outside of two standard deviations for size, intensity, or other metrics of the historical disturbance regime (Romme et al., 1998; Turner and Dale, 1998) and have disproportionate effects on society.

We have also come to understand disturbance regimes as emergent behaviors of complex systems (Falk et al., 2007; McKenzie and Kennedy, 2011; Newman et al., in review). From the perspective of complexity science, it becomes obvious that we can neither perfectly predict future disturbance events nor control their outcomes. Disturbance regimes may not be drastically altered except through total conversion of ecosystems or through crossing major thresholds in biotic and abiotic conditions. Disturbance regimes may be a kind of what complexity scientists call a "strange attractor," that is, a state toward which complex systems will evolve, regardless of initial conditions. Concretely, this means that complex systems such as ecosystems cannot be managed toward single goals far outside of the current state. This idea has been raised for ecosystems previously (Scheffer and Carpenter, 2003) but has not, to my knowledge, been applied to disturbance regimes. Because the earth-climate system has not yet equilibrated to anthropogenic changes, we should not look at current conditions as a new normal, but instead try to map the trajectory of developing and changing disturbance regimes (Scheffer and Carpenter, 2003; Hastings and Wysham, 2010).

\section{CONSERVATION AND MANAGEMENT APPROACHES: MANAGING BIODIVERSITY OVER THE DISTURBANCE CYCLE}

In certain climate-altered disturbance regimes (such as wildfire in the western United States), the idea that certain ecosystems have already passed a point of no return has led to discussions of abandoning large-scale attempts to actively manage natural ecosystems for native biodiversity or human well-being. Instead, exclusively focusing on adapting human societies to the altered disturbance regimes (Adger et al., 2005; Schoennagel et al., 2017) would likely improve outcomes for human lives, communities, and property. However, where and when possible, conserving historical disturbance regimes will be vital to conserving native biodiversity and functioning ecosystems that have evolved with those conditions (Franklin, 1993; Attiwill, 1994; Mori, 2011), and might still be used in certain situations to avoid native biodiversity loss. These "whereas and whens" may be the minority of ecosystem situations and may only be tractable in cases of lowintensity wildfires and some areas where flooding can be avoided.

If treated like an "umbrella species", conserving disturbance regimes as an overarching goal could satisfy many conservation goals simultaneously (Perera et al., 2007). The disturbance-based management approach, as observed by North and Keeton (North and Keeton, 2008), "has two potential benefits that traditional silvicultural practices often lack: variability and adaptation to current conditions." That said, evaluating the outcomes of managing in emulation of the natural disturbance regime can be difficult (Franklin, 1993; Lindenmayer et al., 2008), and it may not be possible to do so beyond certain thresholds and tipping points (Lindenmayer et al., 2008). Successful applications of these ideas are taking hold in a few places, including disturbance regimes of fire, wind, and insects in the boreal forest of Canada (Kneeshaw et al., 2008; Grandpré et al., 2018), and prescribed fire substituting for wildfire in the southeastern pine forests of the United States (for example Glitzenstein et al., 1995) and in the management of wildfire in Sierra mixed conifer forests in North America (see, for example, Collins and Stephens, 2007).

It is also important to recognize that there are undesirable outcomes in ecosystems where well-intentioned managers have taken actions that are based on outdated assumptions and are contrary to what the "best available science" says about the natural disturbance regime. These challenges are present in current conditions and will be more contentious in future climate conditions, where there are multiple, simultaneous goals in place for humans and biodiversity. For example, burning and clearing of California chaparral is still widely done by state and federal land management agencies with the ostensible purpose of lowering wildfire risk, which degrades the ecosystem, simultaneously lowering biodiversity and increasing the fire risk it is meant to contain (Keeley, 2002, 2006; Newman et al., 2018a). Likewise, salvage harvesting in post-wildfire or post-hurricane forested ecosystems may be intended to reduce further risks. However, such "activities undermine many of the ecosystem benefits of major disturbances" by removing biomass and critical habitat and by altering the disturbance legacy of a site, thereby changing long-term biotic and abiotic conditions, which can in turn lead to more severe mortality of organisms in subsequent disturbances (Lindenmayer et al., 2004). The degradation of conditions for the persistence of biodiversity by altering pre- and post-disturbance landscapes will inevitably lead to endangerment of additional species and ecosystems (Noss et al., 2006).

Because the effects of changing disturbance regimes under global change are different in different regions, appropriate management responses will vary from region to region and even within an ecosystem. Now and in future conditions, no single national-level policy for managers can be considered appropriate. Even currently, where appropriate science is available, management plans are often misapplied or applied too broadly. Commenting on undesirable effects of management plans in the USA, Stephens (Stephens, 2005) offers that “... existing federal fire policies frequently do not differentiate between geographical areas or forest types, [and forest type] $\ldots$ is one of the most significant and most misunderstood elements of the decision about where to implement specific fire management policies." Devising an overall management framework that respects historical disturbance regimes and that applies equally well-everywhere is probably not possible. However, as disturbance regimes change, a few guidelines may help with the logic behind creating management plans in an uncertain future: (1) Managing for biodiversity over the life cycle of the longest-lived (and longest-time-to-reproduction) 
organisms may make sense as a "clock" for management in many cases. (2) Treatments that worked historically to achieve certain goals may have new, unintended consequences. (3) Ecosystems that did not evolve with disturbance regimes or particular disturbance types should be prioritized for protection from novel disturbances and anthropogenic change (such as karst ecosystems, e.g., Harding and Ford, 1993; Tuyet, 2001; Urich, 2002; and the interaction of wet montane and tropical cloud forests with wildfire, e.g., Newman et al., 2018b). (4) Some ecosystems with historical disturbance regimes (such as Mediterranean-type shrublands) may be sensitive to additional induced disturbances. (5) Ecosystems naturally have variability and patchiness, so making artificial disturbances conform to uniform treatments and regular schedules may become a form of "farming" and must be avoided (this applies to management implemented through the use of modern technology applied at large scales, such as aerially deployed ignitions or mastication for fire management, but excludes human-natural systems such as savannah maintenance by prescribed fire). (6) Habitat removal as a management strategy (as sometimes applied to shrublands) must also be avoided because of its harmful effects on biodiversity.

\section{FRAMING THE POLICY CONVERSATION AROUND DISTURBANCE ECOLOGY}

Management and policy are two aspects of how society choses to interact with disturbance regimes. Changing disturbance regimes have led to large-scale, after-the-fact policy responses and emergency relief efforts, which do not necessarily address the underlying problem of changing disturbance regimes. In some cases, responses may lead to no change in, or worsening of, the underlying problem, as when relief efforts lead to housing being rebuilt on hurricane floodplains or in zones of known high wildfire activity. This implies that we are in what social scientists call a "wicked problem" (Hammer et al., 2009), which "refer[s] to that class of social system problems which are illformulated, where the information is confusing, where there are many clients and decision makers with conflicting values, and where the ramifications in the whole system are thoroughly confusing" (Churchman, 1967). These types of problems are open to exploitation by "easy-fix" suggestions that arise primarily out of industry profit motive or political self-aggrandizement and are not ecologically sound.

It is imperative that disturbance ecologists critically evaluate such profit-driven "solutions." The need for during- and afterdisturbance relief efforts raises immediate demands, and without large-scale and long-term planning, these demands are likely to dominate the conversation of what to do about communities currently vulnerable to changing disturbance regimes. Relief efforts that do not address adaptation will make the wicked problem of changing disturbance regimes even more intractable. For example, the term "fire-industrial complex" has been coined by Timothy Ingalsbee (Lueck, 2012) to draw attention to the fire suppression and logging efforts (as distinct from ecologically motivated thinning treatments) that were incentivized by US government agencies and the US timber industry, ultimately making the wildfire problem worse. Firefighting in the US is a multibillion-dollar industry, and attempting to create a more ecologically sound practice within it will be challenging (Hudson, 2011). As technology advances, we may face more of these "easy solutions" and profit-driven incentives in response to complex problems. Given what we know about plant functional traits and disturbance ecology, trees modified to be resistant to insect attacks or store greater quantities of carbon would likely be truly catastrophic in wildfire situations (and have other unintended effects on disturbance regimes). The unintended consequences of widespread use of such plants-modified specifically to alter traits that have ecosystem-level consequences, whether through conventional breeding or newer transgenic technologies-may further endanger ecosystems in ways that disturbance ecologists have the knowledge and skills to predict.

The knowledge and perspectives of disturbance ecology are vital to address challenges posed to human well-being and biodiversity by changing disturbance regimes. For well-being, in many cases, the best outcomes will involve the adaptation of human societies to disturbance regimes (Schoennagel et al., 2017) and will require both short- and long-term planning ahead of disturbances, with the recognition that not all outcomes are simultaneously possible and not all values can be protected (Gill et al., 2013). Policy regarding wild ecosystems in changing disturbance regimes should include ahead-of-event planning and protection of human values but equally incorporate the protection of biodiversity that has evolved in natural disturbance regimes. Successful policies regarding changing disturbance regimes for biodiversity will not merely be reactive and will recognize that for natural ecosystems as for human society, not all desired outcomes are simultaneously possible. Disturbance ecology as a field has been tremendously successful over the past several decades at revealing how disturbance regimes and events affect biodiversity and ecosystems, knowledge of which is essential to any attempt to protect human lives, property, and biodiversity in the face of changing disturbance regimes. It is incumbent on disturbance ecologists to articulate this knowledge to societies and governments at large. This includes actively proposing management and policies at local, regional, and federal levels and responding to proposed management and policies that lack disturbance ecology perspectives.

\section{AUTHOR CONTRIBUTIONS}

The author confirms being the sole contributor of this work and has approved it for publication.

\section{FUNDING}

This work was funded in part by the Bridging Biodiversity and Conservation program at the University of Arizona.

\section{ACKNOWLEDGMENTS}

I thank David Hembry and Don McKenzie for discussion and edits to the manuscript. I also thank Don Falk and Brian Enquist for useful discussions. 


\section{REFERENCES}

Adger, W. N., Arnell, N. W., and Tompkins, E. L. (2005). Adapting to climate change: perspectives across scales. Glob. Environ. Change Part A 15, 75-76. doi: 10.1016/j.gloenvcha.2005.03.001

Allen, C. D., Breshears, D. D., and McDowell, N. G. (2015). On underestimation of global vulnerability to tree mortality and forest die-off from hotter drought in the Anthropocene. Ecosphere 6, 1-55. doi: 10.1890/ES15-00203.1

Attiwill, P. M. (1994). The disturbance of forest ecosystems: the ecological basis for conservative management. For. Ecol. Manage. 63, 247-300. doi: 10.1016/0378-1127(94)90114-7

Balch, J. K., Bradley, B. A., Abatzoglou, J. T., Nagy, R. C., Fusco, E. J., and Mahood, A. L. (2017). Human-started wildfires expand the fire niche across the United States. Proc. Natl. Acad. Sci. U.S.A. 114, 2946-2951. doi: 10.1073/pnas.1617394114

Bowler, D., Bjorkmann, A., Dornelas, M., Myers-Smith, I., Navarro, L., Niamir, A., et al. (2018). The geography of the Anthropocene differs between the land and the sea. bioRxiv [preprint]. bioRxiv: 432880. doi: 10.1101/432880

Churchman, C. W. (1967). Guest editorial: wicked problems. Manag. Sci. 14, 141-142 doi: 10.1287/mnsc.14.4.B141

Collins, B. M., and Stephens, S. L. (2007). Managing natural wildfires in Sierra Nevada wilderness areas. Front. Ecol. Environ. 5, 523-527. doi: 10.1890/070007

Emanuel, K. (2018). 100 years of progress in tropical cyclone research. Meteor. Mon. 59, 15-11. doi: 10.1175/AMSMONOGRAPHS-D-18-0016.1

Falk, D. A., Miller, C., McKenzie, D., and Black, A. E. (2007). Cross-scale analysis of fire regimes. Ecosystems 10, 809-823. doi: 10.1007/s10021-007-9070-7

Flannigan, M., Cantin, A. S., De Groot, W. J., Wotton, M., Newbery, A., and Gowman, L. M. (2013). Global wildland fire season severity in the 21st century. For. Ecol. Manage. 294, 54-61. doi: 10.1016/j.foreco.2012.10.022

Franklin, J. F. (1993). Preserving biodiversity: species, ecosystems, or landscapes? Ecol. Appl. 3, 202-205. doi: 10.2307/1941820

Gill, A. M., Stephens, S. L., and Cary, G. J. (2013). The worldwide "wildfire" problem. Ecol. Appl. 23, 438-454. doi: 10.1890/10-2213.1

Glitzenstein, J. S., Platt, W. J., and Streng, D. R. (1995). Effects of fire regime and habitat on tree dynamics in north Florida longleaf pine savannas. Ecol. Monogr. 65, 441-476. doi: 10.2307/2963498

Grandpré, L., Waldron, K., Bouchard, M., Gauthier, S., Beaudet, M., and Ruel, J. C. (2018). Incorporating insect and wind disturbances in a natural disturbance-based management framework for the boreal forest. Forests 9:471. doi: $10.3390 /$ f9080471

Hammer, R. B., Stewart, S. I., and Radeloff, V. C. (2009). Demographic trends, the wildland-urban interface, and wildfire management. Soc. Nat. Resour. 22, 777-782. doi: 10.1080/08941920802714042

Harding, K. A., and Ford, D. C. (1993). Impacts of primary deforestation upon limestone slopes in northern Vancouver Island, British Columbia. Environ. Geol. 21, 137-143. doi: 10.1007/BF00775297

Hastings, A., and Wysham, D. B. (2010). Regime shifts in ecological systems can occur with no warning. Ecol. Lett. 13, 464-472. doi: 10.1111/j.1461-0248.2010.01439.x

Hessburg, P. F., Reynolds, K. M., Salter, R. B., and Richmond, M. B. (2004). "Using a decision support system to estimate departures of present forest landscape patterns from historical reference condition-an example from the inland Northwest region of the United States," in Emulating Natural Forest Landscape Disturbances: Concepts and Applications, eds A. H. Perera, L. J. Buse, and M. G. Weber (New York, NY: Columbia University Press), 158-175.

Hudson, M. (2011). Fire Management in the American West: Forest Politics and the Rise of Megafires. Boulder, CO: University Press of Colorado.

IPCC (2014). Climate Change 2014: Synthesis Report. Contribution of Working Groups I, II and III to the Fifth Assessment Report of the Intergovernmental Panel on Climate Change. eds R. K. Pachauri and L. A. Meyer (Geneva: IPCC; Core Writing Team).

Johnstone, J. F., Allen, C. D., Franklin, J. F., Frelich, L. E., Harvey, B. J., and Higuera, P. E., et al. (2016). Changing disturbance regimes, ecological memory, and forest resilience. Front. Ecol. Environ. 14, 369-378. doi: 10.1002/fee.1311

Keane, R. E., Hessburg, P. F., Landres, P. B., and Swanson, F. J. (2009). The use of historical range and variability (HRV) in landscape management. For. Ecol. Manag. 258, 1025-1037. doi: 10.1016/j.foreco.2009.05.035
Keeley, J. E. (2002). Fire management of California shrubland landscapes. Environ Manage. 9, 395-408. doi: 10.1007/s00267-001-0034-Y

Keeley, J. E. (2006). Fire management impacts on invasive plants in the western United States. Conserv. Biol. 20, 375-384. doi: $10.1111 / j .1523-1739.2006 .00339 . x$

Kneeshaw, D. D., Lauzon, E., de Römer, A., Reyes, G., Belle-Ile, J., Messier, J., et al. (2008). "Appliquer des connaissances sur les régimes de perturbations naturelles pour développer une foresterie qui s'inspire de la nature dans le sud de la péninsule Gaspésienne. pp. 215-240," in Aménagement forestier écosystémique en forêt boréale: pour une foresterie qui séduque de la dynamique naturelle de la forêt. ed. S. Gauthier (Québec, QC: Presses de l'Université du Québec), 568.

Landres, P. B., Morgan, P., and Swanson, F. J. (1999). Overview of the use of natural variability concepts in managing ecological systems. Ecol. Appl. 9, 1179-1188. doi: 10.1890/1051-0761(1999)009[1179:OOTUON]2.0.CO;2

Lindenmayer, D., Hobbs, R. J., Montague-Drake, R., Alexandra, J., Bennett, A., and Burgman, M., et al. (2008). A checklist for ecological management of landscapes for conservation. Ecol. Lett. 11, 78-91. doi: 10.1111/j.1461-0248.2007.01114.x

Lindenmayer, D. B., Foster, D. R., Franklin, J. F., Hunter, M. L., Noss, R. F., and Schmiegelow, F. A., et al. (2004). Salvage harvesting policies after natural disturbance. Science 303:1303. doi: 10.1126/science.1093438

Littell, J. S., McKenzie, D., Peterson, D. L., and Westerling, A. L. (2009). Climate and wildfire area burned in western U.S. ecoprovinces, 1916-2003. Ecol. Appl. 19, 1003-1021. doi: 10.1890/07-1183.1

Lueck, D. (2012). "Economics and the organization of wildfire suppression," in Wildfire Policy: Law and Economics Perspectives, eds K. Bradshaw and D. Lueck (New York, NY: RFF Press), 71-88. doi: 10.4324/9780203153048

Matusick, G., Ruthrof, K. X., Kala, J., Brouwers, N. C., Breshears, D. D., and Hardy, G. E. S. J. (2018). Chronic historical drought legacy exacerbates tree mortality and crown dieback during acute heatwave-compounded drought. Environ. Res. Lett. 13:095002. doi: 10.1088/1748-9326/aad8cb

McKenzie, D., and Kennedy, M. C. (2011). "Scaling laws and complexity in fire regimes," in The Landscape Ecology of Fire eds D. McKenzie, C. Miller, and D. A. Falk (Dordrecht: Springer), 27-49. doi: 10.1007/978-94-007-0301-8_2

McKenzie, D., and Littell, J. S. (2017). Climate change and the eco-hydrology of fire: will area burned increase in a warming western USA? Ecol. Appl. 27, 26-36. doi: 10.1002/eap. 1420

Meehl, G. A., and Tebaldi, C. (2004). More intense, more frequent, and longer lasting heat waves in the 21st century. Science 305, 994-997. doi: $10.1126 /$ science. 1098704

Morgan, P., Aplet, G. H., Haufler, J. B., Humphries, H. C., Moore, M. M., and Wilson, W. D. (1994). Historical range of variability: a useful tool for evaluating ecosystem change. J. Sustain. Forest. 2, 87-111. doi: 10.1300/J091v02n01_04

Mori, A. S. (2011). Ecosystem management based on natural disturbances: hierarchical context and non-equilibrium paradigm. J. Appl. Ecol. 48, 280-292. doi: 10.1111/j.1365-2664.2010.01956.x

Moritz, M. A., Parisien, M. A., Batllori, E., Krawchuk, M. A., Van Dorn, J., Ganz, D. J., et al (2012). Climate change and disruptions to global fire activity. Ecosphere 3, 1-22. doi: 10.1890/ES11-00345.1

Newman, E. A., Potts, J. B., Tingley, M. W., Vaughn, C., and Stephens, S. L. (2018a). Chaparral bird community responses to prescribed fire and shrub removal in three management seasons. J. Appl. Ecol. 55, 1615-1625. doi: $10.1111 / 1365-2664.13099$

Newman, E. A., Winkler, C. A., and Hembry, D. H. (2018b). Effects of anthropogenic wildfire in low-elevation Pacific island vegetation communities in French Polynesia. Peer J. 6:e5114. doi: 10.7717/ peerj. 5114

North, M., and Keeton, W. (2008). "Emulating natural disturbance regimes: an emerging approach for sustainable forest management," in Landscape Ecology: Sustainable Management of Forest Landscapes, eds R. J. Lafortezza, G. Chen, Sanesi, and Crow T. (Berlin: Springer-Verlag Press), 341-372. doi: 10.1007/978-1-4020-8504-8_19

Noss, R. F., Franklin, J. F., Baker, W. L., Schoennagel, T., and Moyle, P. B. (2006). Managing fire-prone forests in the western United States. Front. Ecol. Environ. 4, 481-487. doi: 10.1890/1540-9295(2006)4[481:MFFITW]2.0.CO;2

Pausas, J. G., and Vallejo, V. R. (1999). "The role of fire in European mediterranean ecosystems," in Remote Sensing of Large Wildfires in the 
European Mediterranean Basin, ed E. Chuvico (Berlin; Heidelberg: Springer), 3-16. doi: 10.1007/978-3-642-60164-4_2

Perera, A. H., Buse, L. J., and Weber, M. G. (eds.). (2007). Emulating Natural Forest Landscape Disturbances: Concepts and Applications. New York, NY: Columbia University Press. doi: 10.7312/pere12916

Romme, W. H., Everham, E. H., Frelich, L. E., Moritz, M. A., and Sparks, R. E. (1998). Are large, infrequent disturbances qualitatively different from small, frequent disturbances? Ecosystems 1, 524-534. doi: 10.1007/s1002199 00048

Scheffer, M., and Carpenter, S. R. (2003). Catastrophic regime shifts in ecosystems: linking theory to observation. Trends Ecol. Evol. 18, 648-656. doi: 10.1016/j.tree.2003.09.002

Schoennagel, T., Balch, J. K., Brenkert-Smith, H., Dennison, P. E., Harvey, B. J., Krawchuk, M. A., et al. (2017). Adapt to more wildfire in western North American forests as climate changes. Proc. Natl. Acad. Sci. U.S.A. 114, 4582-4590. doi: 10.1073/pnas.1617464114

Schwilk, D. W., and Ackerly, D. D. (2001). Flammability and serotiny as strategies: correlated evolution in pines. Oikos 94, 326-336. doi: 10.1034/j.1600-0706.2001.940213.x

Sommerfeld, A., Senf, C., Buma, B., D’Amato, A. W., Després, T., Díaz-Hormazábal, I., et al. (2018). Patterns and drivers of recent disturbances across the temperate forest biome. Nat. Commun. 9:4355. doi: 10.1038/s41467-018-06788-9

Stephens, S. L. (2005). Forest fire causes and extent on United States Forest Service lands. Int. J. Wildland Fire. 14, 213-222. doi: 10.1071/WF04006

Syphard, A. D., Radeloff, V. C., Hawbaker, T. J., and Stewart, S. I. (2009). Conservation threats due to human-caused increases in fire frequency in Mediterranean-climate ecosystems. Conserv. Biol. 23, 758-769. doi: 10.1111/j.1523-1739.2009.01223.x

Turner, M. G. (2010). Disturbance and landscape dynamics in a changing world. Ecology 91, 2833-2849. doi: 10.1890/10-0097.1

Turner, M. G., and Dale, V. H. (1998). Comparing large, infrequent disturbances: what have we learned? Ecosystems 1, 493-496. doi: 10.1007/s100219900045
Tuyet, D. (2001). Characteristics of karst ecosystems of Vietnam and their vulnerability to human impact. Acta Geol. Sin.-Engl. 75, 325-329. doi: 10.1111/j.1755-6724.2001.tb0 0539.x

Urich, P. B. (2002). Land Use in Karst Terrain: Review of Impacts of Primary Activities on Temperate Karst Ecosystems. Wellington: Department of Conservation.

Waters, C. N., Zalasiewicz, J., Summerhayes, C., Barnosky, A. D., Poirier, C., Gałuszka, A., et al. (2016). The Anthropocene is functionally and stratigraphically distinct from the Holocene. Science 351:aad2622. doi: $10.1126 /$ science.aad2622

Webster, P. J., Holland, G. J., Curry, J. A., and Chang, H. R. (2005). Changes in tropical cyclone number, duration, and intensity in a warming environment. Science 309, 1844-1846. doi: 10.1126/science.1 116448

White, P. S., and Pickett, S. T. A. (1985). "Natural disturbance and patch dynamics: an introduction," in The Ecology of Natural Disturbance and Patch Dynamics, eds S. T. A. Pickett and P. S. White (New York, NY: Academic Press), 3-13. doi: 10.1016/B978-0-12-554520-4.50006-X

Conflict of Interest Statement: The author declares that the research was conducted in the absence of any commercial or financial relationships that could be construed as a potential conflict of interest.

The reviewer, TS, declared a shared affiliation, with no collaboration, with the author to the handling editor at the time of review

Copyright (c) 2019 Newman. This is an open-access article distributed under the terms of the Creative Commons Attribution License (CC BY). The use, distribution or reproduction in other forums is permitted, provided the original author $(s)$ and the copyright owner(s) are credited and that the original publication in this journal is cited, in accordance with accepted academic practice. No use, distribution or reproduction is permitted which does not comply with these terms. 